\title{
Intelligent Products to Support Closed-loop Reverse Logistics
}

\author{
Karl A. Hribernik ${ }^{1}$, Moritz von Stietencron ${ }^{1}$, Carl Hans ${ }^{1}$, Klaus-Dieter Thoben ${ }^{1}$ \\ ${ }^{1}$ BIBA - Bremer Institut für Produktion und Logistik GmbH, Bremen, Germany
}

\begin{abstract}
This paper aims to show that Intelligent Products may be used to facilitate closed-loop reverse logistics processes. An analysis of the actors and processes in reverse logistics processes is presented to identify requirements towards the characteristics of a technical concept suitable to support closed-loop reverse logistics processes. That Intelligent Products fulfill the requirements is shown by presenting use cases in selected application scenarios. A critical evaluation of the applicability of the results of the analysis of the actors and processes and their implications for the design of Intelligent Products concludes the contribution.
\end{abstract}

Keywords:

Closed-loop product lifecycle management, Intelligent products, Sustainability

\section{BACKGROUND AND MOTIVATION}

Sustainability and consequently reverse logistics has become a vitally important topic for today's economy. The dramatic increase in global demand for raw materials in contrast with dwindling natural resources, the impact of waste on the ecosystem coupled with the resulting repercussions for society combine to put pressure on industry to develop more sustainable products and services. Moreover, European customers increasingly insist upon such sustainable products and services. Consequently, sustainability has also become a significant marketing instrument, used to attract customers with terms such as "Green Production". One example of this is how Apple, Inc. advertises its products using a lifecycle-wide analysis of their emitted pollutants. [1] Unfortunately, the unscrupulous use of sustainability topics in advertising is gaining increasing notoriety and has coined the term "Greenwashing". [2]

European Union legislation obliges manufacturers to establish organizational concepts which are supported by suitable technological infrastructures to ensure the profitability of affected products. For example, EU Directive 2002/95/EG restricts the use of hazardous substances in electrical and electronic equipment [3] This directive has been implemented as various national legislations throughout Europe, for example in Germany as the "Elektro- und Elektronikgerätegesetz." [4] Furthermore, the recycling of waste electrical and electronic equipment (WEEE) is promoted by the EU Directive 2002/96/EG. [5]

Since 2003, the disposal of used cars is also regulated by the European Union. Besides directives regarding the use of heavy metals in automobiles, Directive 2000/53/EC specifies the minimum allowable quotient for the reuse end-of-life vehicles. [6] On average, $95 \%$ of the average weight of a vehicle is to be reusable by the year 2015. Again, this directive is implemented in European national laws, for example in the German "Altfahrzeug-Verordnung" or used vehicle act. [7]

Last but most definitely not least, the main benefit for companies implementing reverse logistics processes is a significant return-oninvestment. One example is the resale of used products to customers with lower demands towards quality. Refurbishing, the reuse of individual product components and the recycling of raw materials are other examples of how otherwise "useless" products can be monetised beyond the ends of their lives. [8]

Whatever approach is taken to increase the sustainability of a product, it generally implies adopting a holistic perspective upon its entire lifecycle. This means that the interest and investment of the manufacturing company needs to be extended beyond the product's beginning-of-life (BOL) not only into its middle-of-life (MOL) when it in use and possibly serviced, but also into its end-oflife (EOL) when it is ultimately decommissioned and disposed of. The consequence of this is the need for an information management approach which facilitates knowledge of the product's status at any point in its lifecycle. Additionally, information loops need to be closed between the individual lifecycle phases (BOL, $\mathrm{MOL}$ and $\mathrm{EOL}$ ), processes and stakeholders in order to create added value by acting the managed lifecycle information.

This paper aims to show how Intelligent Products may be used to facilitate closed-loop reverse logistics processes. An analysis of the actors and processes in reverse logistics processes is presented to identify requirements towards the characteristics of Intelligent Products suitable to support closed-loop reverse logistics processes. Exemplary Intelligent Products fulfilling the requirements are presented in application scenarios. A critical evaluation of the applicability of Intelligent Products to reverse logistics processes concludes the contribution.

\section{RELATED WORK}

This section presents an overview of related work in literature. It begins with a look at the topic of reverse logistics in general. Subsequently, the state-of-the-art in closed-loop product lifecycle management is discussed. To conclude this section, a brief summary of currents definitions and applications of intelligent products is laid out. 


\subsection{Product Lifecycle}

A number of different perspectives towards the product lifecycle exist. Literature broadly differentiates marketing and production engineering ones. [9] The marketing perspective tends to adopt a sales-oriented view upon the product lifecycle, in which the lifecycle is divided into the Introduction, growth, maturity, saturation and degeneration of a product. Here the product seen not as a physical thing only in terms of the degree of its economic success. [10] The scope a product refers to in this view may be a model, type or category.

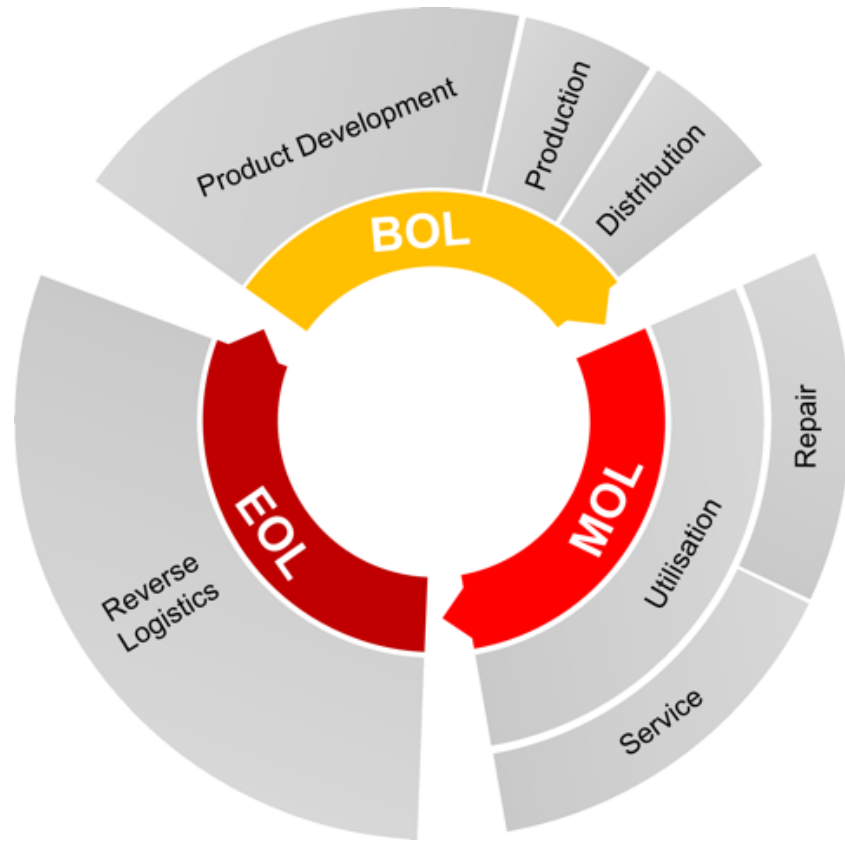

Figure 1: The Three Phases of the Product Lifecycle.

The production engineering perspective used here follows [11] and is shown in Figure 1. In this model, the processes related to the development, production and distribution of the product are arranged into the beginning-of-life (BOL) phase. A product's utilisation, service and repair are labelled middle-of-life (MOL). Finally, reverse logistics processes take place in the end-of-life (EOL) phase.

\subsection{Product Lifecycle Management}

Organisational, economic and IT perspectives as well as some more comprehensive views towards product lifecycle management (PLM) are widespread. Today, organisational views highlight the management of lifecycle knowledge in distributed, multidisciplinary and cooperative teams in extended enterprises. [12], [13] Economic views stress the business activity of effectively managing a company's product through their entire lifecycle, from the ideation to disposal, i.e. from "cradle to grave". [14], [15], [16] The aim here is to increase product revenues, reduce product-related costs, and maximize the value of the product portfolio.

From an IT perspective, Product Lifecycle Management (PLM) is commonly understood as a concept which "seeks to extend the reach of PDM [...] beyond design and manufacturing into other areas like marketing, sale and after sale service, and at the same time addresses all the stakeholders of the product throughout its lifecycle." [16] Classic PDM functionality encompasses object, component and document management, classification and search functionality, change management and tools for system administration and configuration. [17] PLM consequently encompasses strategically modelling, capturing, exchanging and using information and data in all decision-making processes throughout the product lifecycle. [14], [18] It implements an integrated, cooperative and collaborative management of product data along the entire product lifecycle. [19]

\subsection{Reverse Logistics}

Once a product has fulfilled its original use, it is decommissioned and enters into the "disposal" or EOL phase of its lifecycle. The processes which EOL consists of are generally summarised with the term "reverse logistics". However, the term is not always used coherently in literature. The following exemplify the main schools of thought in the field. Kroon and Vrijens define reverse logistics as "the logistic management skills and activities involved in reducing, managing and disposing of hazardous or non-hazardous waste from packaging and products." [20] In this definition, on the one hand logistics activities such as the transportation of a product to the disposal plant and on the other processing tasks such as repairing a product for reuse are conflated in the term. This definition furthermore encompasses organisational processes. In contrast, Dowlatshahi [21] focuses more specifically on logistics processes: "Reverse logistics is a process in which a manufacturer systematically accepts previously shipped products or parts from the point for consumption for possible recycling, remanufacturing, or disposal." Furthermore, a reverse logistics system encompasses a "supply chain that has been redesigned to manage the flow of products or parts destined for remanufacturing, recycling or disposal." [ibid.] A supply chain is generally understood to span manufacturers, suppliers, all intermediate stakeholders and concludes with the end customer. In the field of reverse logistics this idea is reflected in concept of the reverse supply chain, i.e. the expended product is transported "back" either to the beginning of a "new lifecycle" or towards its terminal disposal. [22], [23] Both positions are summarised by Fleischmann, et al. [24] Here, reverse logistics "encompasses the logistics activities all the way from used products to no longer required by the user products to products again useable in the markets." This approach to reverse logistics closes the loop in the material flow from EOL to BOL.

\subsection{Closed-loop Product Lifecycle Management}

Traditionally, IT solutions supporting PLM focus on classes of products and variants rather than individual items. Furthermore, they mostly address the initial phases of the lifecycle. They offer document, workflow and project management functionality. This approach renders their potential for enhancing reverse logistics processes limited from the perspective of the seamless availability of data, information and knowledge from the entire product lifecycle, including MOL and EOL phases.

Many different technical and non-technical approaches address reverse logistics processes. One which has raised significant industry attention is the concept of Closed-loop Product Lifecycle Management. [25] Closed-loop PLM describes an approach to PLM which facilitates the closing of information loops between the individual phases of the product lifecycle. It aims to achieve a pervasive availability of relevant product information at any point in the product lifecycle. Furthermore, the concept deals with closing information loops between different IT layers, from the data acquisition, through middleware and knowledge transformation layers to the business application layer. In order to do so, the concept proposes different methods of applying information technology. [26], [27], [28], [29], [30] With Closed-loop PLM, a paradigm shift from "cradle to grave" to "cradle to cradle" is put forward. [31]

\subsection{Intelligent Products}

"Intelligent Products" are physical items, which may be transported, processed or used and which comprise the ability to act in an 
intelligent manner. McFarlane et al. define the Intelligent Product as "a physical and information based representation of an item [...] which possesses a unique identification, is capable of communicating effectively with its environment, can retain or store data about itself, deploys a language to display its features, production requirements, etc., and is capable of participating in or making decisions relevant to its own destiny." [32] The degree of intelligence an intelligent product may exhibit varies from simple data processing to complex pro-active behaviour. This is the focus of the definitions in [32] and [33]. Based on these definitions, the level of Intelligence of Intelligent Products can be divided into three dimensions and characterised as follows: [34] Information Handling, Event Notification and Decision Making. This is the first dimension of the Intelligent Product. When each object has its own intelligence, it does not necessary mean that the intelligence is located at the object. In the second dimension, two extremes can be identified: Intelligence through the Network and Intelligence at the object. Finally, the third dimension of the Intelligent Product is the aggregation level of the product intelligence. In general, two levels can be differentiated: Item level and Container level.

\section{ANALYSIS OF THE PROCESSES AND ACTORS IN REVERSE LOGISTICS}

The review of related work presented above shows that current IT solutions supporting PLM are often not adequate for the management of item-specific product information beyond BOL. This is mainly due to the fundamental changes in the context of the product and the resulting consequences for data management approaches. During the conception and the production phase, only a few stakeholders are involved in the management of product data. These either belong to a single organisation or are tightly coupled to the IT landscape prescribed by the main stakeholder. Responsibility for the product lies with the manufacturer, who also grants physical access to it. The data models and management systems used serve a limited amount of well-known tasks and objectives which are dictated by the manufacturer coordinating the PLM network. It follows that, in order to develop an IT concept capable of supporting PLM in the EOL phase, first a sound understanding of the processes and actors involved in reverse logistics needs to be developed.

\subsection{Methodology}

In order to comprehensively identify the processes and actors in EOL, the first step was a thorough analysis of general EOL descriptions and use cases and in literature. First, UML (Unified Modelling Language) Use Case diagrams were used in order to capture the actors involved in EOL activities. In a second step, the processes themselves were modelled as BPMN (Business Process Modelling Notation) diagrams. The aim of the application of the methodology was to achieve as generic a view of EOL processes and actors as possible. The focus was laid upon identifying processes and actors common to a wide range of reverse logistics cases. Consequently, very individual characteristics of specialised, domain-specific EOL processes and actors were subsumed under more generic headings where possible. The following sections present the results of the identification of processes and actors.

\subsection{Categorisation of the Processes and Actors of Reverse Logistics}

The identified categories are shown in Figure 2 integrated into the product lifecycle model from Figure 1. On the top right of the EOL process segment, the preparatory processes common to all reverse logistics cases are grouped. These encompass the decommissioning of a product, its collection, sorting and inspection. At the bottom, the organisational and logistics processes which permeate the entire EOL phase from decommissioning to the creation of a new product are shown. These include, for example, all intra-logistics processes in which products, component parts and materials are transported through end-of-life processes, as well as the organization, managerial and financial control of the reverse logistics processes. Finally, the core EOL processes are illustrated on the top left of the EOL segment in Figure 2.

After identifying the processes in EOL in literature and modelling them using BPMN, the next step was to develop a system of categorisation. A harmonisation of terminology was required, due to the often inconsistent use in literature. For example, "recycling" is often used to describe reverse logistics in general, whereas it can also carry the specific meaning of breaking products down into raw materials. The resulting categorisation is meant to be applicable to a wide spectrum of products and consequently does not drill deeply into detailed process layers.

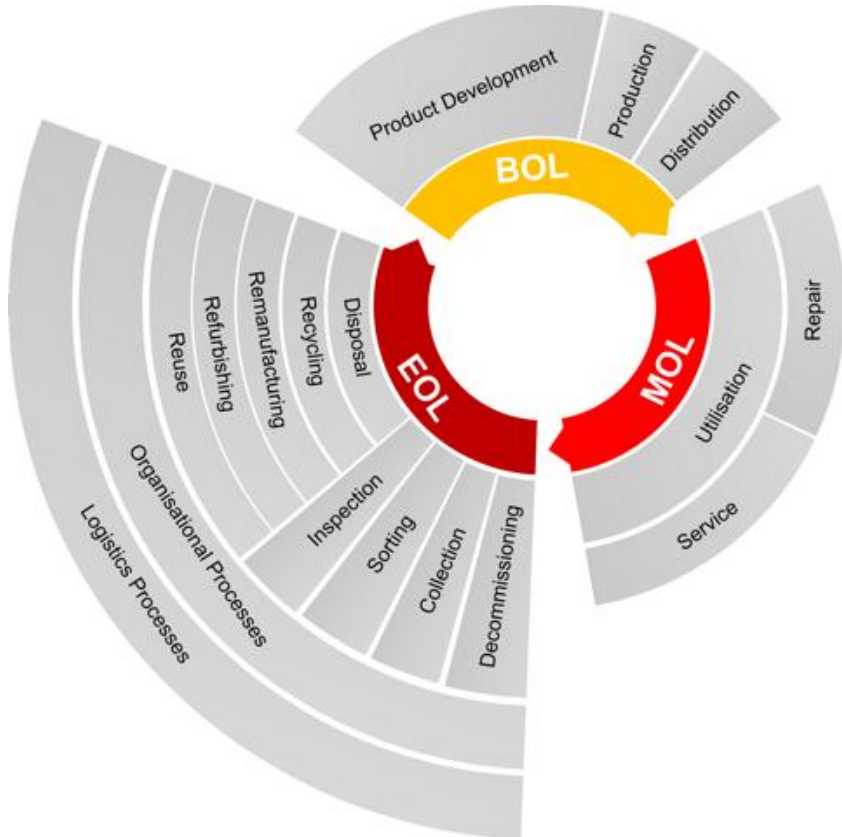

Figure 2: Reverse Logistics Processes in the Product Lifecycle.

In its most simple form, Reuse describes the redistribution of a product without extensive post-processing. Two alternatives are possible - the whole product or individual component parts may be reused. Refurbishing means the overhauling of a product before it is redistributed. Similar to reuse, this process may be applied to the whole or parts of a product. Also, some parts may be overhauled whilst others are simply reused. The aim of Remanufacturing is to make a product or parts thereof new. This means, some components of the product might be replaced with new ones. A remanufactured product should fulfil the same quality standard as a new product. Whereas the previously described core processes target the reinstatement of the product's original functionality, Recycling disregards this aspect. The aim here is to break down the product into as homogeneous as possible raw materials. These raw materials may then be used to create new products in a further loop of the product lifecycle.

As touched upon above, a single product may be dismantled and its individual components may be introduced to different core EOL processes. Also, the target lifecycle phase may be different from product to product. A refurbished product, for example, may be returned to the original owner or resold in retail. These flows are illustrated in Figure 3. Here, circular nodes represent XOR decisions, and square nodes OR decisions. 


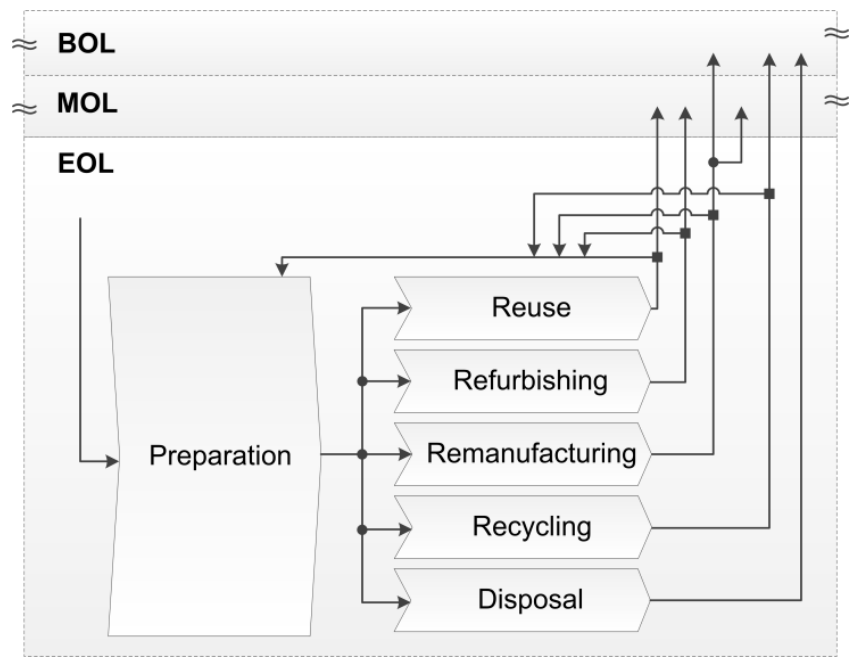

Figure 3: Process Sequence in Reverse Logistics.

The distribution of actors across the individual reverse logistics processes is shown in Table 1. These actors consequently participate in all four preparatory processes. In some sectors, the municipality may be responsible for organising the decommissioning of certain goods. Examples can be found in communal waste collection. Reverse logistics plant workers are also involved in all of these processes except for decommissioning. They are also involved in all of the core processes, as are the executives and vendors of EOL plants. Executives and workers at service providers providing reverse logistics services are involved in the collection process, as well as the logistics processes underlying the core processes. The logistics executives are furthermore responsible for organisational processes. In some cases the logistics actors may be the same as the plant actors.

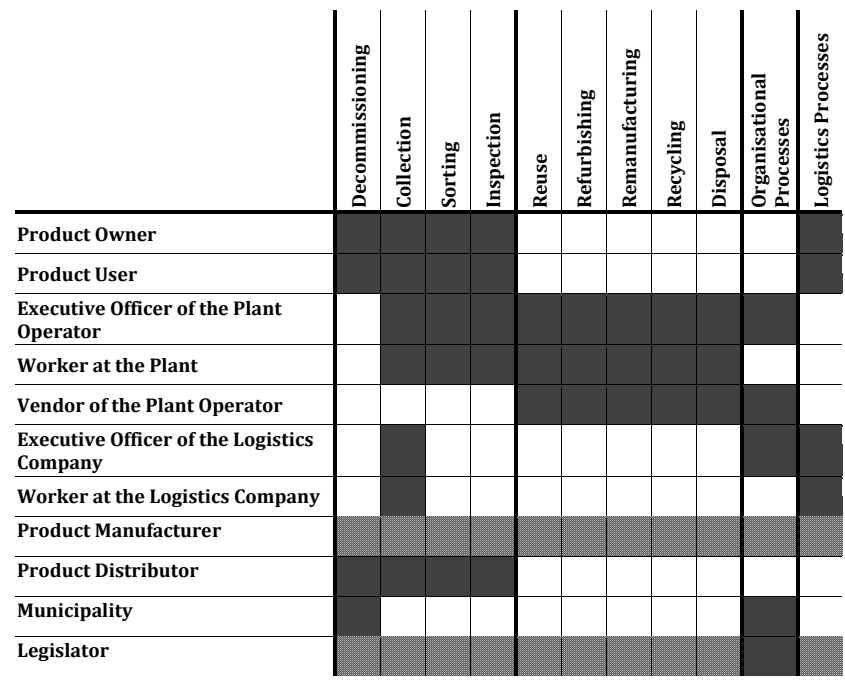

Table 1: Distribution of Actors over Reverse Logistics Processes.

The product manufacturer is a special case. For most products, the manufacturer is not directly involved in reverse logistics processes. At best the manufacturer will subcontract service providers to carry out EOL activities. There are however, cases in which the manufacturer deals with EOL directly. In this case, the reverse logistics plant and logistics operators may belong to the manufacturer. In any case, the manufacturer's product design and production choices directly affect the type of reverse logistics processes the product can be introduced to at EOL. Finally, legislation influences all processes, but acts directly only in an organisational manner.

\section{IMPLICATIONS FOR CLOSED-LOOP REVERSE LOGISTICS}

The above analysis reveals that reverse logistics processes encompass preparatory processes such as decommissioning, collection, sorting and inspection, the core end-of-life processes such as reuse, refurbishing, remanufacturing, recycling, and disposal, as well as the auxiliary organizational and logistics processes. Here, approaches to information management are often less developed than in other fields of logistics. The characteristics of the stakeholders involved in reverse logistics identified in Table 1 processes exacerbate this problem. For example, manufacturers are often involved only in the initialization of end-of-life processes and have little contact with recycling contractors. This lack of an integrated information management approach leads not only to inefficiency in the end-of-life processes themselves but also to the neglect of information sources which may be of value to other processes in the product lifecycle.

\subsection{Closing EOL Information Loops with Intelligent Products}

It follows that such a Closed-loop Product Lifecycle Management approach necessitates an IT concept and infrastructure capable of acquiring, transmitting and managing such information for individual products throughout their entire lifecycles. A technological means is required to integrate the disparate actors and respective information systems across the product lifecycle. Often, the product or component part to be disposed of is the sole link between all of the product's stakeholders. One promising concept to address this problem may be found in Intelligent Products. By implementing identification and information processing capability directly into products and component parts, information may be exchanged to and from reverse logistics processes.

\subsection{Use Cases of Exemplary Intelligent Products}

The following two use cases exemplify their use in sectors in which, as described in section 1, legislative and societal pressure is high to find solutions for more sustainable products - the automotive and electronic and electrical goods sectors. The first exemplary use case of closing information loops in reverse logistics with Intelligent Products deals with the recycling of plastic automotive parts. The second deals with the lifecycle management of electronic equipment including reverse logistics processes.

\section{Recycling Plastic Automotive Parts}

In this use case, a continuous product information management is achieved by means of RFID and sensor-based Intelligent Products from the usage phase, over the preparatory and core reverse logistics processes back into the BOL phase of a new product. Plastic automotive parts are heterogeneous goods which are transported employing a variety of containers. In this use case, two forms of Intelligent Product are used. Firstly, Product Embedded Information Devices (PEIDs, for example RFID tags) are embedded into the plastic parts in order to both identify the type of part and the material it is made of and to track any changes made to the material by repairs, service or replacement in the usage phase. Secondly, the recycled material is also made "intelligent". In this case, embedded devices are packed in such a way that they are immersed within the recycled material (plastic granulate), as shown in Figure 4. These embedded devices provide unique product identification, memory for the storage of product data and sensor facilities, for example a thermometer for the monitoring of easily inflammable plastic granulates. The embedded devices establish a wireless connection available to devices equipped with suitable readers. Terminals are used as an example of such devices and are understood to represent PDAs, workstations or stand-alone 
readers connected to the main enterprise systems. For example, PDAs or other devices can be employed e.g. by shop floor personnel or logistics operators to carry out a number of operations upon information transmitted by the embedded devices. These devices are then used as relay stations to backend systems through a dedicated middleware layer which in turn provides input to a Decision Support and Product Data Management system.

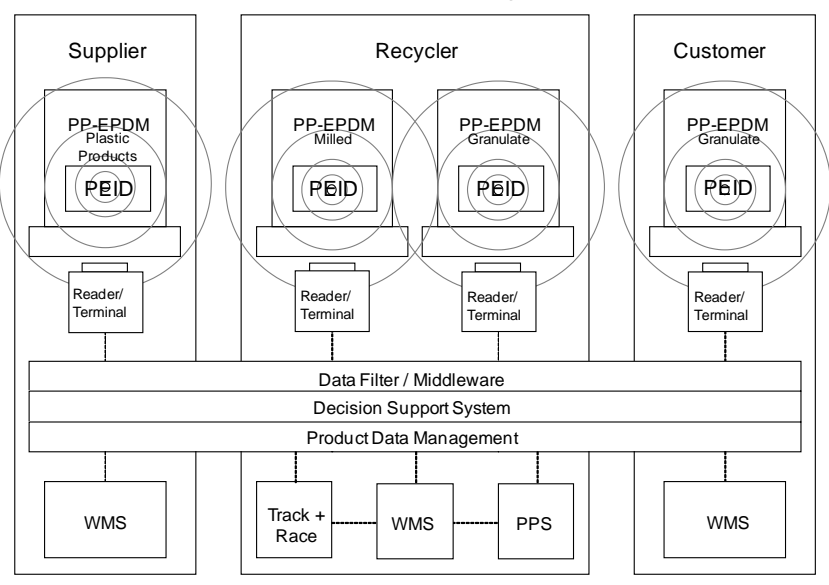

Figure 4: Intelligent Products in EOL of Plastic Automotive Parts.

\section{Reverse Logistics of Electronic Goods}

This use case exemplifies the application of RFID-based Intelligent Products in the field of electronic goods. It encompasses the entire product lifecycle, from the assembly of the electronic product, through its usage phase into the preparatory and core reverse logistics processes. The electronic product comprises of a chassis upon which a mainboard, a processor, an ISDN modem, a mains unit, a display and a hard drive are mounted. Each needs to be handled separately in EOL, dictating the requirement of an individual tracking and tracing of each component throughout the product lifecycle. Furthermore, the management of the aggregation of these components comprising the main product needs to be taken into account, allowing for the management of parts replacement and maintenance in the middle, usage phase of the product's lifecycle.

Each of the component parts is assigned a unique identifier which, stored on an RFID chip applied to each component, is used to track and trace the components throughout the lifecycle. On this basis, each individual object can be tracked independently and real-time information about each individual object can be collected, stored and acted upon. In order to enable cooperation partners to seamlessly query such information throughout the product lifecycle, including the collaboration partners in the EOL phase, a standard interface to that information is required. This may be realised using e.g. EPCIS (Electronic Product Code Information Services) or PMI (PROMISE Message Interface). In EOL, the Intelligent Product is decommissioned, decomposed, and its individual product parts selected for recycling, refurbishing, reuse or disposal. Using the information stored on the RFID and the data generated throughout the lifecycle, component parts can be precisely identified and disposed of, the type of disposal along with the time need to be documented in order to fulfil legal requirements. By leveraging EPCIS or PMI, the precise time, location and responsibility details of the decomposition operation can be recorded (cf. Figure 5), along with information regarding the type of disposal (for example recycle, refurbish, or reuse). The event information can be used by the manufacturer and the part suppliers to document their fulfilment of their legal obligations to provide suitable disposal services which satisfy their legal obligations.
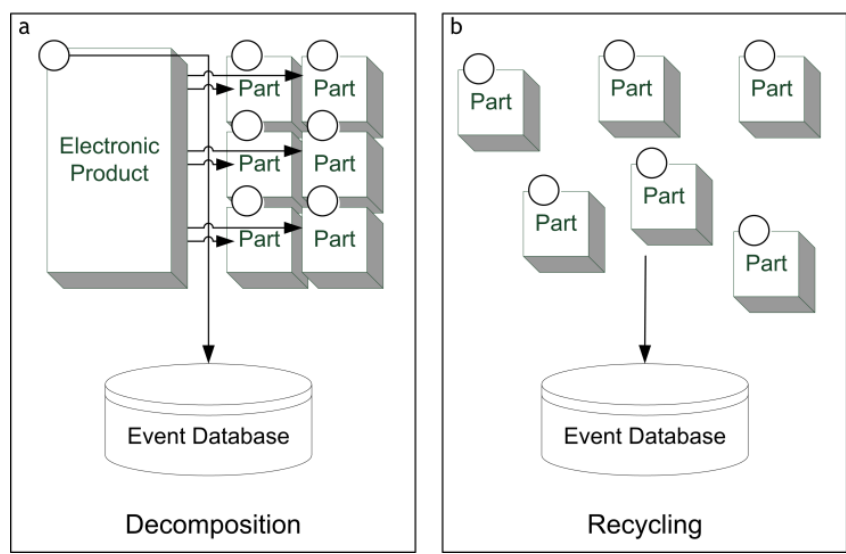

Figure 5: Example of EOL Events in EOL (Decomposition).

\section{CONCLUSIONS AND OUTLOOK}

This contribution has presented the results of an analysis of the processes and actors in reverse logistics. It has shown that closing the information loops arising between BOL, MOL and EOL and in EOL itself is difficult due to the distribution of actors across the processes. On that basis it has suggested Intelligent Products as potentially beneficial for closing the information loops found in reverse logistics and achieving an integrated closed-loop PLM. Two use cases from prominent sectors of industry with relation to sustainability demonstrate the feasibility of that approach.

The categorisation of reverse logistics processes and the actors involved is, as previously mentioned, a generic, high-level view of the EOL phase. It is designed to be applicable to a wide range of products. However, it cannot do justice to the details of highly specialised EOL processes in each sector.

Consequently, future work in this area could include a detailed analysis of the processes and actors in individual sectors of industry. On this basis, a complimentary categorisation of the required characteristics of Intelligent Products to fulfil the requirements of individual types of products in these sectors could be established.

\section{ACKNOWLEDGMENTS}

This research was partially funded by the German Research Foundation (DFG) within the Collaborative Research Centre 637 Autonomous Cooperating Logistics Processes - A Paradigm Shift and its Limitations.

\section{REFERENCES}

[1] Apple Inc. (2010) Environmentally Friendly Design. The Internet. http://www.apple.com/imac/environment.html. accessed 08.09.2010.

[2] Laufer, W. S. (2003) Social accountability and corporate greenwashing. In: Journal of Business Ethics 43, Nr. 3, pp. 253-261.

[3] European Union (2003) Directive 2002/95/EC of the European Parliament and Council of the 27 January 2003 on the restriction of the use of certain hazardous substances in electrical and electronic equipment (ROHS). Official Journal of the European Union. The Internet: http://eurlex.europa.eu/LexUriServ/LexUriServ.do?uri=OJ:L:2003:037: 0019:0023:en:PDF Accessed 18.11.2010. 
[4] Bundesministerium der Justiz (2005) Gesetz über das Inverkehrbringen, die Rücknahme und die umweltverträgliche Entsorgung von Elektro- und Elektronikgeräten (Elektro- und Elektronikgerätegesetz - ElektroG), Berlin.

[5] European Union (2003) Directive 2002/96/EC of the European Parliament and Council of the 27 January 2003 on waste electrical and electronic equipment (WEEE). Official Journal of the European Union. The Internet: http://eurlex.europa.eu/LexUriServ/LexUriServ.do?uri=OJ:L:2003:037: 0024:0038:en:PDF Accessed 18.11.2010.

[6] European Union (2003) Directive 2000/53/EC of the European Parliament and Council of the 27 January 2003 on end-of-life vehicles. Official Journal of the European Union. The Internet: http://eurlex.europa.eu/LexUriServ/LexUriServ.do?uri=CONSLEG:200 0L0053:20050701:EN:PDF Accessed 18.11.2010.

[7] Bundesministerium der Justiz (2001) Verordnung über die Überlassung, Rücknahme und umweltverträgliche Entsorgung von Altfahrzeugen (Altfahrzeug-Verordnung AltfahrzeugV), Berlin.

[8] Schultmann, F.; Zumkeller, M.; Rentz, O. (2006) Modeling reverse logistic tasks within closed-loop supply chains: An example from the automotive industry. In: European Journal of Operational Research. 171, Nr. 3, pp. 1033-1050.

[9] Sundin, E. (2009) Life-Cycle Perspectives of Product/ServiceSystems: In Design Theory. In: Introduction to Product/Service-System Design. London: Springer, pp. 31-49

[10] Meffert, H.; Burmann, C.; Kirchgeorg, M. (2008) Marketing: Grundlagen marktorientierter Unternehmensführung Konzepte - Instrumente - Praxisbeispiele. 10. Aufl. Wiesbaden: Gabler.

[11] Kiritsis, D.; Bufardi, A.; Xirouchakis, P. (2003) Research issues on product lifecycle management and information tracking using smart embedded systems. In: Advanced Engineering Informatics 17, Nr. 3-4, pp. 189-202

[12] Terzi, S., Ball, P. D., Bouras, A., Dutta, D., Garetti, M., Gurumoorthy, B., et al. (2008) A new point of view on Product Lifecycle Management. In Proc. of 5th International Conference on Product Lifecycle Management, Seoul, Korea.

[13] Garetti, M., Terzi, S., Bertacci, N., Brianza, M. (2005) Organisational change and knowledge management in PLM implementation. International Journal of Product Lifecycle Management, 1(1), pp.43-51.

[14] Stark, J. (2005) Making Progress with PLM. A Manual to Support PLM Initiatives and PLM Projects. John Stark Associates

[15] Gomes, J., Vallejos, R. (2007) Applying a benchmarking method to organize the product lifecycle management for aeronautic suppliers. In M. Garetti, S. Terzi, P. D. Ball \& S. Han (Eds.), Product Lifecycle Management Special Publication 3, pp. 3-10. Bergamo/Milano.

[16] Golovatchev, J. D., Budde, O. (2007) A holistic Product Lifecycle Management framework facing the challenges of 21 st century. Paper presented at the 3rd International Conference on Lifecycle Management, ZurichAmeri, F.; Dutta, D. (2005) Product Lifecycle Management - Closing the Knowledge Loops. Computer-Aided Design and Applications 2 (5). pp. 577-590.

[17] Abramovici, M.; Sieg, O. (2001) PDM - Technologie im Wandel - Stand und Entwicklungsperspektiven. Orientierung für die Praxis. Industrie Management 17, Nr. 3. pp. 71-75.
[18] Moorthy, A., Vivekanand, S. (2007): Integration of PLM with other concepts for empowering business environments. In M. Garetti, S. Terzi, P. D. Ball S. Han (Eds.), Product Lifecycle Management Special Publication 3, pp. 93. Bergamo/Milano.

[19] Terzi, S., Panetto, H., Morel, G., Garetti, M. (2007) A holonic metamodel for product traceabily in Product Lifecycle Management. International Journal of Product Lifecycle Management, 2(3), pp. 253-289.

[20] Kroon, L.; Vrijens, G. (1995): Returnable containers: an example of reverse logistics. In: International Journal of Physical Distribution \& Logistics, Nr. 2, pp. 56-68.

[21] Dowlatshahi, S. (2000) Developing a theory of reverse logistics. In: Interfaces.30, Nr. 3, pp. 143-155.

[22] Blackburn, J. D.; Guide, V. D.; Souza, G. C.; Van Wassenhove, L. N. (2004) Reverse supply chains for commercial returns. In: California Management Review 46, Nr. 2, pp. 6-22.

[23] Nagurney, A.; Toyasaki, F. (2005) Reverse supply chain management and electronic waste recycling: a multitiered network equilibrium framework for e-cycling. In: Transportation Research Part E: Logistics and Transportation Review. 41, Nr. 1, pp. 1-28.

[24] Fleischmann, M.; Bloemhof-Ruwaard, J. M. ; Dekker, R. ; Van Der Laan, E. ; Van Nunen, J. A. ; Van Wassenhove, L. N. (1997) Quantitative models for reverse logistics: a review. In: European Journal of Operational Research 103, Nr. 1, pp. 117

[25] Hong-Bae, J.; Kiritsis, D.; Xirouchakis, P. (2007) Research Issues on Closed-loop PLM. Computers in Industry, December 2007: pp. 855-868.

[26] Quantitative models for reverse logistics: a review. In: European Journal of Operational Research Bd. 103 X, 1, S. $1-17$

[27] Hans, C.; Hribernik, K. A.; Thoben, K. D. (2010): Improving Reverse Logistics Processes Using Item-level Product Lifecycle Management. In: International Journal of Product Lifecycle Management

[28] Jun, H. B.; Kiritsis, D.; Xirouchakis, P. (2007) Research issues on closed-loop PLM. In: Computers in industry .58 (89), pp. $855-868$

[29] Kiritsis, D. (2010) Closed loop PLM for intelligent products in the era of the internet of things. In: Computer-Aided Design, DOI: 10.1016/j.cad.2010.03.002.

[30] Jun, H. B.; Shin, J. H.; Kiritsis, D.; Xirouchakis, P. (2007) System architecture for closed-loop PLM. In: International Journal of Computer Integrated Manufacturing 20 (7), pp. 684-698.

[31] Pokharel, S.; Mutha, A. (2009) Perspectives in reverse logistics: A review. In: Resources, Conservation and Recycling. 53, Nr. 4, pp. 175-182

[32] McFarlane, D., Sarma, S., Chirn, J. L., Wong, C. Y., Ashton, K. (2003) Auto ID systems and intelligent manufacturing control, Engineering Applications of Artificial Intelligence 16 (4) pp. 365-376.

[33] Kärkkäinen, M., Holmström, J., Främling, K., Artto, K. (2003) Intelligent products - a step towards a more effective project delivery chain, Computers in Industry 50 (2) (2003) pp. 141151.

[34] Meyer, G. G., Främling, K., Holmström, J. (2009) Intelligent Products: A Survey, Computers in Industry 60 (3) pp. 137-148 